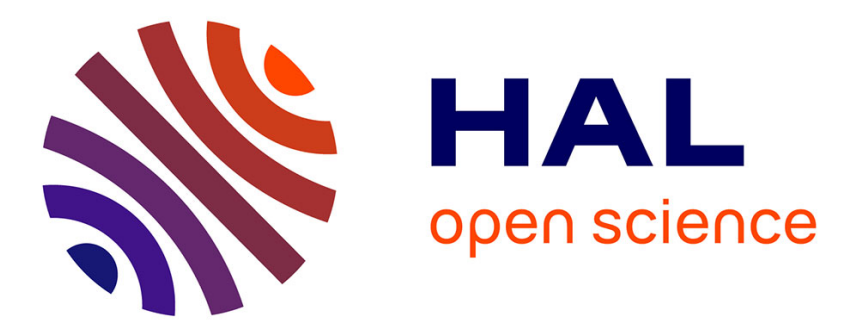

\title{
ARE LOCAL TEACHERS REQUIRED WITHIN MOOCS SESSIONS?
}

Jean-Charles Canonne, Jean-Paul Becar, Aurel Fratu, Mariana Fratu

\section{To cite this version:}

Jean-Charles Canonne, Jean-Paul Becar, Aurel Fratu, Mariana Fratu. ARE LOCAL TEACHERS REQUIRED WITHIN MOOCS SESSIONS?. INTED 2016, iated, Mar 2016, Valencia, Spain. hal02508371

\section{HAL Id: hal-02508371 \\ https://uphf.hal.science/hal-02508371}

Submitted on 14 Mar 2020

HAL is a multi-disciplinary open access archive for the deposit and dissemination of scientific research documents, whether they are published or not. The documents may come from teaching and research institutions in France or abroad, or from public or private research centers.
L'archive ouverte pluridisciplinaire HAL, est destinée au dépôt et à la diffusion de documents scientifiques de niveau recherche, publiés ou non, émanant des établissements d'enseignement et de recherche français ou étrangers, des laboratoires publics ou privés. 


\author{
ARE LOCAL TEACHERS REQUIRED WITHIN MOOCS SESSIONS? \\ Jean-Charles Canonne ${ }^{1}$, Jean-Paul Bécar ${ }^{1}$, Aurel Fratu ${ }^{2}$, Mariana Fratu ${ }^{2}$ \\ ${ }^{1}$ University of Valenciennes (France) \\ ${ }^{2}$ Transilvania University of Brasov(Romania)
}

\begin{abstract}
The paper deals with the connection between the classical teachings and a modern one known as MOOC for Massive Online Open Course. This paper reports the experiences made at our Institute of Technology in using MOOC to improve our academic achievement. Students from the two first years of the Bachelor in Electrical Engineering and Computing Science are concerned with these experiences. The students have to perform a mentored project each semester. Within this framework some students have been asked to attend MOOCs on subjects that were not exactly in the schedule of the Bachelor. Two MOOCs were provided by the Queensland University of Technology (www.qut.edu.au) and the professor Peter Corke (www.petercorke.com) and were dealing with robotics and vision, the third $\mathrm{MOOC}$ was organized by the Ecole Polytechnique Fédérale de Lausanne (www.epfl.ch), and was an introduction to programming in $\mathrm{C}_{++}$. The keen interest of students for these subjects is a first explanation for the success the experiences encountered, but this explanation must be completed and therefore we are going to give a more precise description of the experiences to enlighten the reasons of their success. Each experience has been organized with approximately the same timetable. A first meeting has been organized two weeks before the beginning of the MOOC. During this meeting, the local team of lecturers explained the subject of the MOOC and gave prerequisite knowledge: for example, for the first MOOC about robotics, lecturers gave explanations about matrices and Matlab. The first meeting was also devoted to the organization of the following weeks: when and where will the participants meet, who were the teachers involved, how could these lecturers help, and so on...As soon as the MOOC has begun, all local participants spent half a day together each week, each one first working on his own and then discussing about the problems he had encountered. The local multidisciplinary team is important for students who need knowledge in different domains, but also appreciate to see how a lecturer can work and progress in a subject he is not specialized in. This part of the work has to be managed by teachers in the same way as an athletic training, and this coaching is the key of the important rate of success of our students in regard with the MOOCs. The last meeting occurred one week after the MOOC had ended and consisted in an evaluation of the MOOC and of the work made. This meeting gave us ideas for further works.
\end{abstract}

Keywords: MOOC, project based learning, motivations, technology, robotics teachings, $\mathrm{C}_{++}$ programming, multidisciplinary.

\title{
1 INTRODUCTION
}

Since a couple of decades, authors are running towards the vanishing student motivations. They have applied a large amount of teachings tools or methods as the slide rule, the overhead projector, the programmable calculator, software, the internet, Moodle and supervised projects. Project based learning is one of them. Initially used in an Erasmus background, that is placement in a foreign partner university for 3-4 months, the project based learning technique is now applied in projects supervised by local lecturers. The main goal is to increase the autonomy of students. Recently, a group of lecturers planned new experiences in teaching methods. They wanted to apply the project based learning technique inside the academic syllabus denoted as a mentored project. Another reason was to see how MOOC in particular and e-learning in general could interact with lecturers, and more precisely how they can reinforce one another [1].

Students from the two first years of the Bachelor in Electrical Engineering and Computing Science are concerned with these experiences. The students have to perform a mentored project every semester. The paper deals with the connection between the classical teachings and a modern one known as MOOC. The term MOOC stands for Massive Online Open Courses. This paper reports the experiences made at an Institute of Technology in using MOOC to improve our academic achievement. 
Within this framework some students have been asked to attend MOOCs on subjects that were not exactly in the schedule of the Bachelor. Two MOOCs were provided by the Queensland University of Technology (www.qut.edu.au) and the professor Peter Corke (www.petercorke.com )and were dealing with robotics and vision, the third MOOC was organized by the Ecole Polytechnique Fédérale de Lausanne (www.epfl.ch), and was an introduction to programming in $\mathrm{C}_{++}$. The section 2 presents the Institute of Technology in France and the mentored project activity written in the academic syllabus locally illustrated in the Electrical Engineering Department. The section 3 is talking about the first MOOCs [2]. The MOOCs concern here over ten thousand worldwide participants. In the Institute of Technology, two groups have been formed for the MOOC. A local one composed of six students from first year course in Electrical Engineering domain. Four Finnish students in second grade in Information Technology course form the second group. Their three months stay in France has been possible thanks to the Erasmus+ students exchange. Students have been supervised weekly by lecturers in Maths, Mechanics, Control and English language all the MOOC long. In the IUT, a group of lecturers have been working together to improve the students' behavior face to sciences. For 20 years the lecturers have shared their experiences on domains as electronics, electrical engineering, process control and applied mathematics. They have tried to find common interests for this aim. Thus the collaboration started with discussions on academic subjects as mathematics applied to electronics, process control and robotics but also on others subjects like the sun trajectory, solar tracker, solar rover, Science Fair, Lego $\odot$ Mindstorms $\odot$ projects and robotics. The common thread for all activities, projects or exchanges, has been how to boost up the motivation of students and increase their concentration. Moreover, the dynamic behavior of the lecturers involved in projects have motivated other colleagues to join the group. The currently number of lecturers involved proves this fact. The section 4 is concerned with a new experience of MOOC in $\mathrm{C}_{++}$programming. A free access to the course is done by the internet. Proud of the success of the first MOOCs focusing on robotics and robotics vision, students and lecturers suggested to take part to another one. The initiation to a high level programming language has been chosen for two main reasons. Firstly, all lectures are given in French language. Secondly, the dynamic group previously formed for the purpose wanted to renew an experience which had given satisfaction. It means that organization, devoted classroom, debriefing meeting, discussions, supervising, advising and mentoring have satisfied everyone. In particular, the discrete, efficient and helpful role of lecturers is a common item mentioned by the group of students. The section 5 draws some conclusions in order to feed discussions and improve the results.

\section{EDUCATIONAL FRAMEWORK}

\subsection{The French Institutes of Technology}

The creation of Institute of Technologies in France was decided on January $7^{\text {th }} 1966$. The aim was to provide French companies with qualified employees specialized in fast developing technologies. These employees should be trained in two years at the University and then employed as qualified technicians to bring help to engineers and companies in their efforts to modernization. Institutes of Technology have now existed for fifty years but they still keep this key role in the transmission of technical progress. This implies for their lecturers the necessity of life-long learning, and to try any opportunity to do so. We can imagine MOOCs are such opportunities.

The creation of Institutes of Technology was also part of territorial management. As Universities are only located in bigger towns, the creation of Institute of Technology in medium-sized cities is an opportunity to bring new technologies everywhere in the country to help local companies. It is also an opportunity to bring more young people to new jobs, in particular people from families with low income, who could not afford studies in bigger and more expansive towns. Institute of Technology and MOOCs have in common the goal of bringing knowledge from big towns to more remote places. The map on Fig.1 shows the geographical breakdown of IUT. 


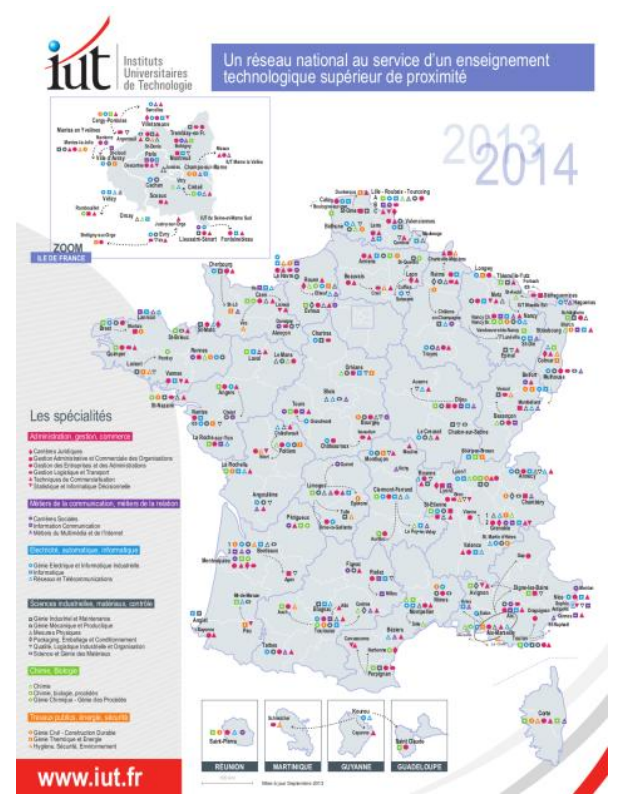

Fig. 1 : The Institutes of Technology in France

\subsection{The Electrical Engineering and Computing Science Department}

The region of Valenciennes is the France's number-one automotive region including seven automaker sites, more than 150 companies and $30 \%$ of national sites production. Our Institute is part of the answer in the search of synergies between educational system and local economy. The Transalley technology park, a cluster for sustainable and innovative mobility, is located in Valenciennes across from the University campus (http://www.transalley.com/en/).

The Institute of Technology of Valenciennes is organized in 9 departments specialized in different domains such as Mechanics, Physical Measuring Procedures, Quality Management... and among these departments our Electronic Engineering and Computing Science department.

Depending on years, the number of students involved in our department for the two years is approximately 150 , equally spread over the two years. Our department also offers third years of specialization not treated in this paper.

All departments of Electrical Engineering and Computing Science have to follow, with a rate of ninety per cent, the same schedule, that is, the so called "PPN", Programme Pédagogique National, in French. This schedule can be found on the internet on the site of the government dedicated to Education. This schedule explains the subjects that have to be taught and how many hours have to be spent on each subject. This schedule is constantly discussed in national meetings involving both lecturers and company managers, looking both at the needs of economy and at local experimentation (http://www.education.gouv.fr/). As a matter of facts, experimentation in education can take place through what the PPN calls the Mentored Projects.

\subsection{The mentored projects}

Every student has to perform a mentored project each semester. These projects are aimed to develop the following skills. The first one is the practical application of knowledge and know-how that is to do documentary research, to propose solutions, to build all or part of a product or service. The second skill is concerned with the experimentation of multidisciplinary that is to use Mathematics in Electronics or English in Automation. A third skill to develop is the learning and practice of project management methodology: to draft specifications, to manage time and deadlines, to communicate. At last teamwork, initiative, communication skills are some student's social skills to be develop in mentored projects.

An illustration of a mentored project is proposed. This each year for More than ten years a couple of teachers have managed the organization and animation of Science Day in Valenciennes. During the first semester students are dispatched in groups of six students. Each group is responsible for a scientific workshop. The group has to imagine, to prepare a workshop and then to animate it during 
Science Day. Children from elementary schools come to the Institute on Science Day, and are dispatched in groups of twelve children in workshops dealing with either robotics, paper folding, cryptography and solar trajectory. All these subjects involve documentary research and multidisciplinary. Students have to improve their project management skills to be ready on time. On top of hat, talking, explaining to pupils and their teachers develop their social skills.

The workshops dedicated to robotics, in particular robotics with Lego@ robots, have always been among the most popular workshops of our Science Day. To meet this demand from both students and pupils, our group of lecturers decided last year to take the opportunity of a MOOC to improve their knowledge in robotics: none of us was specialized in robotics, being instead lecturers in Mathematics, Electronics and Control Theory for example. We proposed some students to attend to the MOOC with us as they were interested in robotics. As robotics is not a subject in our PPN, we suggested that it would be their mentored project for the second semester.

\section{ARE YOU EXPERIENCED WITH MOOCS?}

This section deals with the first MOOC experiences done in the IUT. It sums up the main results of the MOOCs on robotics and robotics vision, focusing mainly on the role of lecturers. One main consequence has been the start of a new $\mathrm{MOOC}$ on the programming language $\mathrm{C}++$.

\subsection{MOOCs in robotics and vision with Queensland University of Technology}

Professor Peter Corke and the Queensland University of Technology have organized a MOOC called "An introduction to Robotics ", that began in February 2015 and has last approximately eight weeks. This MOOC was based on a part of the book written on this subject by Peter Corke [3], and an electronic version of this part of the book was provided if you enrolled the MOOC. A free access to Matlab@ was also provided for the duration of the MOOC. In addition to the MOOC, a non compulsory robotic challenge based on Lego@ Mindstorm@ brick was proposed.

The first week (Week 0) was left to participants to prepare themselves for the MOOC: for example, to install Matlab@, or to get a Lego@ $\odot$ box, or to try the forum of the QUT website, but also to get some prerequisites about linear algebra. The following weeks were each organized in four parts. Part one was devoted to lessons: two hours of videos in English divided in approximately twelve sequences of ten minutes. Participants had possibility to have subtitles in English. The high quality of the videos contributed to the success of the experience: they were more than a filmed course, with scenes taking place out of a classroom, which could recall us of Aristotle walking with his followers. In the second part, every participant had to answer a quiz, which aimed to verify the good understanding of the lessons, and in particular the good understanding of the vocabulary of robotics, and of given Matlab@ instructions that is a kind of translation from Matlab@ to English. The quiz was automatically evaluated, and this evaluation gave points for obtaining the final certificate. In the third part, the student had to write Matlab@ programs to solve theoretical problems of robotics (translation from English to( ), from example to calculate trajectories. The programs where sent to the QUT, and an evaluation of these programs was automatically generated and sent back to the student. This evaluation also gave points for obtaining the final certificate. The last part was not compulsory and was devoted to the Lego@ practical project. For example, week two was dedicated to the design and construction of the Lego@ robot. The last week -week seven- was used to finish the Lego@ project. A robot had been constructed and programmed during the preceding weeks. The challenge was to make the robot draw lines between given points on an A3 format paper. Student had to film it, and send the video on Youtube@ $\odot$. A peer to peer evaluation was organized with other participants.

\subsection{The robotics}

A group of twelve students and three lecturers from our department have enrolled the MOOC. Before the beginning of the MOOC, lectures have been given by the Mathematics lecturer about linear algebra and about Matlab@.

During the MOOC, we had each week half a day for lecturers supervising: English comprehension with the English lecturer, Mathematics explanations with the Mathematics lecturer and Matlab@ help with the Control Process lecturer. This weekly meeting took place in a friendly room equipped with a coffee machine. Students and teachers watched the videos together and discussed about them. It has 
been very important for students to see lecturers learn a new subject: to see how they take down notes for example, or how they dare to say they don't understand. Quiz and programs had to be done at home, but students were invited to work together, and could ask questions either by mail to their lecturers, either by questions on the forum of the MOOC.

This participation to the MOOC has complied with the objectives of the mentored project as described in our syllabus: that are multidisciplinary activities, practical application of knowledge, project management with deadlines and finally teamwork.

The participation to the MOOC has even surpassed the targets.

First of all, students have improved their English language: after three weeks most of them didn't need to use the subtitles. They have also learnt a subject for which our institute had not a high qualified teacher as Peter Corke. On another point, the relationship between lecturers and students, as well students and students has been improved by these eight weeks of common adventure. Lecturers have played coaches, and students players.

More than fifty per cent of students obtained their certificate from the University of Queensland. Such a percentage is very important for a MOOC, and this success is due to the local presence of lecturers. This certificate from an Australian University will be important for them when they will seek a placement or a job.

The MOOC has given students ideas of going abroad to go on studying, which is very important for students who are not used to travelling, and which shows that giving education in rather small towns is not in opposition to opening minds on the World. This experience was so successful that students ask us to participate to the second MOOC organised by Peter Corke on Vision, and that other lecturers and students joined us for this second adventure seen on Fig. 2.

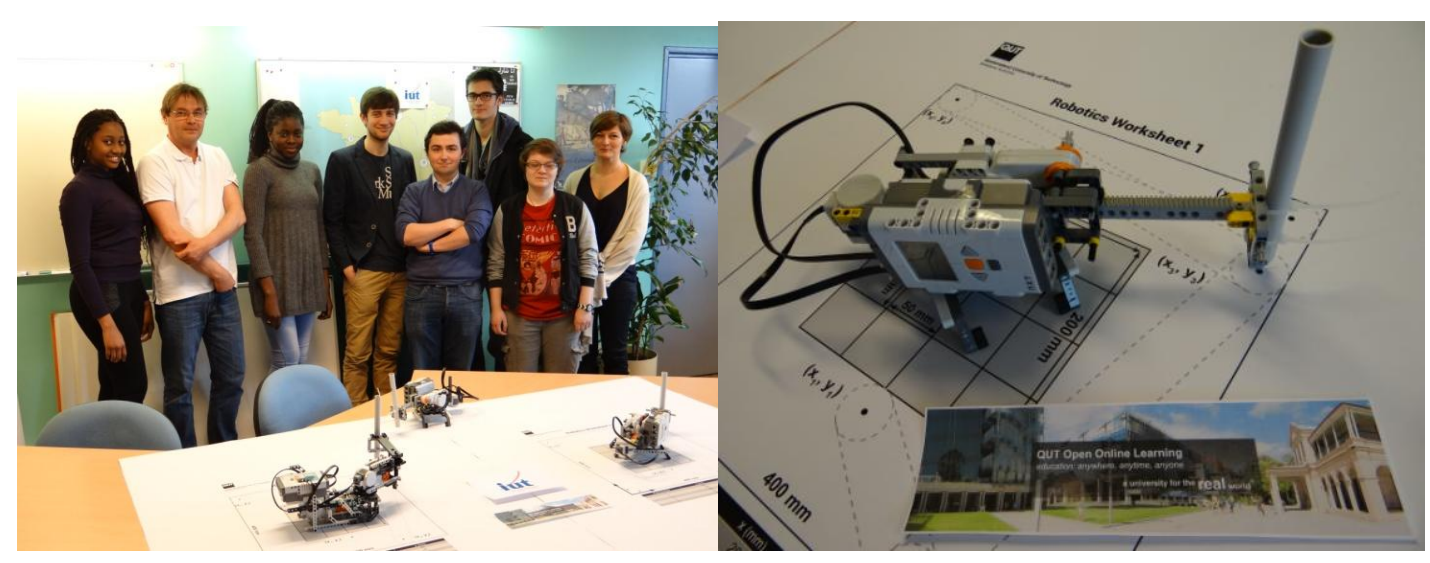

Fig. 2: left: the local team; right: a drawbot

\subsection{The robotic Vision}

The MOOC "Robotic Vision" has also been organized by Professor Peter Corke and the Queensland University of Technology. It began in April 2015 and has last approximately 8 weeks. It had the same organization as the previous MOOC, including lessons on video, quiz, Matlab $\odot$ programming problems and an optional practical work using a webcam. For this practical work, the student had to find the location of shapes of different colors and sizes on an A3 paper using a webcam. An additional project was also proposed using both a webcam and a Lego@ robot: the challenge was to use the robot to draw lines between shapes of different colors that had to be found on an A3 paper, see Fig. 3 .

This MOOC was presented as "an introduction to the field of computer vision and the mathematics and algorithms that underpin it". The goal was to learn how to interpret images to determine the color, size, shape and position of objects in the scene (https://MOOCs.qut.edu.au/learn/robotic-vision-april$\underline{2015}$ ). One more time, Professor Peter Corke invited us to follow him in a very interesting science trip including considerations about human vision, color perception, and 3D perception. We have been given opportunities to learn not only about Robotics, but also about Art, History, Medicine...Far from the academic classroom, Peter Corke invited us to penetrate in the Ames room built at Queensland University of Technology. 
For the second MOOC, four other students and their lecturer working on another mentored project joined us. We were also joined by four Finnish students who were on an Erasmus placement for four months in our department. Our department organizes student exchanges with two Finnish universities: Satakunta University of Applied Sciences, located at Pori, and Oulu University, located at Oulu in the north of Finland. Each year French students go for a three months placement in Finland, and in the same way Finnish students come to Valenciennes. These Finnish students coming to Valenciennes usually work on technical projects involving Lego@ robots, robots in general and robotic vision, and the MOOC was not so far from their project. The French students who joined us were due to go on placement in the university of applied sciences in Oulu, Finland, at the end of the year, and the subject of their work during that placement was robotic vision and image recognition with an international researcher specialist of vision (http://www.ee.oulu.fi/ hadid/Research.html). In the same way the first MOOC had been a good opportunity to make teachers and students work together, the second MOOC made French and Finnish students work together. Once again the second experience proved the importance of local teachers to organize the meetings between all the staff. We noticed that during Easter Holidays, having no coach with them, some students gave up. However, the MOOC was a success and more than fifty per cent of students got their certificate.

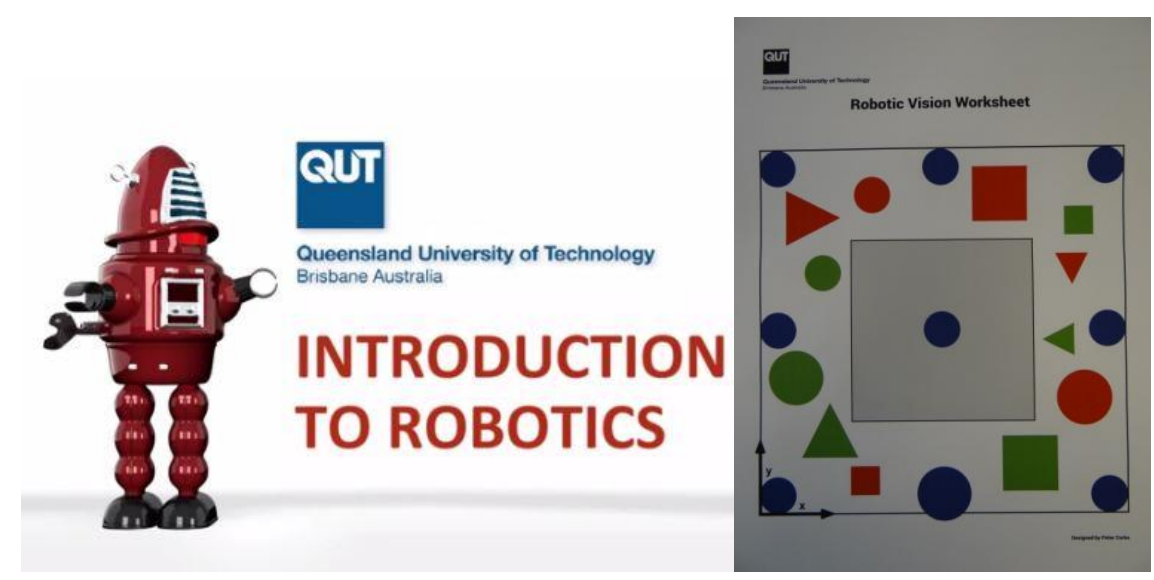

Fig. 3 :Left : Robby at QUT ; Right : robotic vision worksheet

The success of the MOOC in robotics drove the students and their lecturers to enroll in another MOOC taught in French language in order to free students of the English language difficulties.

\section{AS HARD AS A MOOC OR COMPUTING SCIENCE WITH ECOLE POLYTECHNIQUE FEDERALE DE LAUSANNE}

\subsection{The $\mathbf{C + +}$ programming language lessons}

A group of second grade bachelor students decided to take part to the $\mathrm{C}_{++}$programming language lessons (https://www.coursera.org/course/initprogcpp) given through a MOOC by the Ecole Polytechnique Fédérale de Lausanne (https://www.epfl.ch/). The general organization of the MOOC is identical to the previous both. That includes videos lessons, exercises, quizzes, homework and tests followed by assessments and certificates. Locally, the background is quite similar. Two lecturers manage the group of 15 students and participate both to the MOOC. One of them has been teaching computer science in the past, using a schematic representation for the description of algorithms and he has seen the opportunity to refresh his knowledge in applying it to a modern language. Lecturers and students learning the same subject states a first point of motivation. All week long, students do not hesitate to ask technical questions on their current problems.

The Université Polytechnique de Lausanne organizes two MOOCs dealing with the $\mathrm{C}++$ programming language (https://www.coursera.org/course/initprogcpp). We are concerned here with the first one, which is an initiation for students to the high level programming language $\mathrm{C}_{++}$. The second MOOC is an initiation to Oriented Object Programming. The first MOOC lasts eight weeks, requiring over five hours work per week. No previous knowledge is needed. Each week session ends with a quiz, a couple of practical exercises and a homework program to be uploaded within a fixed schedule. A final certificate is given to the students who completed all works in time. 


\subsection{The schedule and pedagogical background}

In parallel of the $\mathrm{C}++$ lessons, the students group is taking academic lessons on the micro processor MSP 430 from Texas Instruments. The micro processor is programmed in C language following the idea of Kernighan and Ritchie who defined the basics of the $C$ language in order to ease applications development such as word processors, calculating sheets or data bases but also applications close to assembly language of a micro. See [3] for details. The book is also known as the K\&R.

The lessons are given by two lecturers. One of them is a specialist on electronics and the second one, who is one of the author of the present article, is a mathematics lecturer. Increasing multidisciplinary is a way to motivate students and lecturers. On the other hand, during the MOOC, the $\mathrm{C}++$ lessons eased the comprehension of the micro controller $C$ language, as both schedules were matching very well. This opportunity also improves communication inside the group. In that situation, the supervising can be done in real time with over 3 days between the informal checking points. The Fig. 4 sums up some of lecturers' tasks done in that background. Some of these tasks are well known [5]. The step 1 is concerned with all MOOC long. It includes the general organization of activities. The step 2 starts when the official is launched on the internet. The step 3 is one of the most important part of the MOOC. At one point students wanted to stop learning lessons due to the difficulty getting harder suddenly. At that time, they asked a technical help from the lecturers. One of them gave them not exactly the solution to homework but a schematic solution using a block representation of algorithm taught at the University. The effect was immediate. All students shared the answer and continued the MOOC lessons. But, the motivation had been restored just a little bit in order to end the MOOC see point 4 in Fig. 4.



Fig. 4 : Teachers tasks for MOOCs

At the end of lessons, ninety percent of the students group obtained the certificate. All MOOC long they wrote on a logged book the tasks done during their hard eight-weeks work, typewrote the report and finally uploaded the report on a website devoted to the copy detection.

The Institute of technology requires from this current academic year that all students working in local companies or learning at partner universities must upload their final report on a special folder. The folder is built by the teacher on a website devoted to analyze the amount of plagiarism in the report. (https://www.compilatio.net/solutions/magister/). The software answers must be carefully studied. Three types of answers are given. A coarse one using traffic light colors, the correct ratio of copy and an accurate description of all text copied including references, websites and all paragraphs taken from the web. The software analyzes all words, sections, references and website written in the report. The lecturer 's folder contains two documents, the student's report itself and the plagiarism detection report. For the $\mathrm{C}_{++}$seminar, the students had been informed of the usage of this software. As results, all traffic lights for any student report were in a green color. 


\section{CONCLUSION}

The paper presents experiences on MOOC usage. The acronym MOOC states for Massive Open Online Course. That means, a set of 2 times 8 lessons of 2 hours each are given through an internet website. The authors are running for decades to the vanishing motivation of their students. For 20 years, they have consumed their energy to find new teachings methods. A yearly national science fair, the sun trajectory programming, an autonomous solar rover, Lego Mindstorms applications, virtual prototyping placement are the main subject in use. The authors are using the project based learning technique. An experience based on a MOOC is described in this paper. The robotics and robotics vision are the subjects. This MOOC is locally concerned with 10 thousand attendants. After the two MOOC sessions, over five hundred listeners obtained the certificate of participation over ten thousand attendants at the beginning. Locally, the questionnaire answers confirm the teachers feeling. The wind of difficulties getting up is blowing the students motivation. Fifty percent of the students group including a girl obtained the certificate of participation. The debriefing with students after the MOOC and the questionnaire answers lights up useful comments. The negative issue states on the second session. The second part of the MOOC has not been attractive for our students for the following reasons: too much workload in addition to their basic work, the French students on first grade are not prepared to be autonomous by comparison to their Finnish friends, a two-week vacation for students, a heavy schedule, difficulties getting up in connection of mathematics, computer science, process control and mechanics, misunderstanding of the English language.

As main positive issue the students mentioned the large availability of their lecturers in real time even on the internet, as one teacher 's participation that keeps going the interest said Justine. On the point of view of students, working alone in front on a screen for videos lessons and access to discussion forum and answers to quizzes and exercises in real time is not sufficient. The students need direct and useful exchanges with the lecturers and their friends in the lab room. This lab room equipped with a coffee pot improves all dialogs inside the group. On the point of view of lecturers, the main effect is due to the multidisciplinary team built for these sessions. The certificate obtained by the students labeled their $\mathrm{cv}$.

Despite of students mentioned the large availability of their lecturers and their skills on computing science, all the group decided not to take part to the second MOOC in the Oriented Object programming. There are two main reasons, they said, why they cancelled their participation. First, the difficulty is getting harder than in the previous MOOC. Secondly, all tasks in programming are time consuming with respect to their own and heavy schedule. But on lecturers' opinion, students are not yet mature enough to learn Oriented Object Programming.

At the starting of this new century, the teaching methods are quickly changing. The use of internet contributes to ease the communication. But teachers make themselves indispensable in live education. According to the era of the Petabyte Age, some authors are predicting the end of that. See (http://www.wired.com/2008/06/pb-theory/) or (https://edge.org/3rd culture/anderson08/) to feed reflection.

\section{AKNOWLEDGEMENTS}

The authors would like to warmly thank the University of Valenciennes and the Institute of Technology for giving the work environment and in particular the availability of the technical staff.

\section{REFERENCES}

[1] Wheeler S., Gerver R., Learning with 'e's: educational theory and practice in the digital age, Crown House Publishing, 2015, ISBN 978-1-84590-939-0

[2] A robotics experience with mooc, Jean-Charles Canonne, Jean-Paul Bécar, Aurel Fratu, Mariana Fratu, iceri2015 proceedings, pp 6420-6425, 2015,ISBN: 978-84-608-2657-6.

[3] Corke P.I., "Robotics, Vision \& Control”, Springer 2011, ISBN 978-3-642-20143-1. .

[4] Kernighan B., Dennis Ritchie D., The C Programming Language (2nd ed.), Englewood Cliffs, NJ: Prentice Hall. (March 1988). ISBN 0-13-1103.

[5] Fochtman, M. M. (2006). Managing, supervising, advising, and mentoring: Each requires unique hat for the professional. Campus Activities Programming (38), 7, p47-52 